\title{
Siirt Koşullarında Kişniş Genotiplerinin Bazı Tarımsal Özelliklerinin Belirlenmesi
}

\author{
Gülen ÖZYAZICI ${ }^{1}$
}

${ }^{1}$ Siirt Üniversitesi, Ziraat Fakültesi, Tarla Bitkileri Bölümü, Siirt

$\bowtie$ : gulenozyazici@siirt.edu.tr

\author{
Geliş (Received): 04.11.2017
}

Kabul (Accepted): 15.12.2017

\begin{abstract}
ÖZET: $\mathrm{Bu}$ araştırma, Siirt şartlarında kişniş genotiplerinin meyve verimi ve bazı tarımsal özelliklerinin belirlenmesi amacıyla Siirt Üniversitesi Ziraat Fakültesi Deneme Alanı'nda tesadüf blokları deneme desenine göre 4 tekerrürlü olarak 2016 yılında yürütülmüştür. Çalışmada Kudret K, Pelmus, Gamze, Erbaa çeşitleri ile Siirt, Irak populasyonlarının meyvaları kullanılmıştır. Araştırmada çıkış süresi, ilk çiçeklenme süresi, vejetasyon süresi, bitki boyu, sap kalınlı̆̆ı, dal sayısı, sayvan (şemsiye) sayısı, sayvanda meyve sayısı, bin meyve ağırlığı, biyolojik verim ve meyve verimi parametreleri incelenmiştir. Araştırma sonuçlarına göre; bitki boyu $51.22-71.70 \mathrm{~cm}$, sap kalınlı̆ 1 1.98-2.34 mm, dal sayıs1 4.92-7.76 adet/bitki, sayvan sayıs1 5.60-9.52 adet/bitki, sayvanda meyve sayıs1 30.21-37.66 adet/bitki, bin meyve ağırlı̆̆ $6.45-9.34 \mathrm{~g}$, biyolojik verim 338.0-614.2 kg da-1, meyve verimi 76.88-119.76 kg da-1, hasat indeksi ise \%18.53-23.36 arasında değişim göstermiştir. Bir adaptasyon denemesi olan bu çalışmada, yapılan varyans analiz sonucuna göre en yüksek meyve verimi Gamze çeşitinde belirlenmiştir.

Anahtar Kelimeler: Kişniş, Coriandrum sativum, çeşit, meyve verimi
\end{abstract}

\section{Determination of Some Agricultural Characteristics of Coriander Genotypes in Siirt Conditions}

ABSTRACT: This research was conducted to determine the effects on yield and some agricultural characteristics of coriander genotypes in Siirt conditions in 2016. The experimental design was the randomized block with four replications. This study was used six genotypes (Kudret K, Pelmus, Gamze, Erbaa, Siirt, Irak). In research was investigated such as emergence time, first flowering period, vegetation period, plant height, stem diameter, number of branches, number of umbel per plant, number of fruit per umbel, 1000 fruit weights, biological yield, seed yield and harvest index. The coriander genotypes were affected significantly in all characteristics except for harvest index. According to research results, plant height, stem diameter, number of branches, number of umbel per plant, number of fruit per umbel, 1000 fruit weights, biological yield, seed yield and harvest index were changed between 51.22$71.70 \mathrm{~cm}, 1.98-2.34 \mathrm{~mm}, 4.92-7.76$ number/plant, 5.60-9.52 number/plant, 30.21-37.66 number/plant, 6.45-9.34 g, $3380.0-6142.0 \mathrm{~kg}$ ha-1, 768.8-1197.6 kg ha-1, 18.53- $23.36 \%$ respectively. In this study, which is an adaptation experiment, the highest fruit yield was determined in the Gamze genotype according to the variance analysis result. Key Words: Coriander, Coriandrum sativum, cultivar, fruit yield

\section{GíRiş}

Kişniş, Akdeniz ve Ortadoğu kökenli tek yıllık önemli bir uçucu yağ bitkisidir. Bitkinin yaprakları ve meyveleri kullanılmaktadır. Kişniş uçucu yağı gıda, sağllk, kozmetik, meşrubat ve çikolata endüstrisinde yaygın olarak kullanılmaktadır. Tohum, yaprak, meyve ve çiçek gibi bitkinin farklı kısımları antibakteriyel, antifungal, antioksidan, diüretik, antiepileptik, antidiyabetik, sedatif, hipnotik, antimutajenik, antimikrobiyal, antihelmintik aktiviteye sahiptir. Fiziksel özellikleri, kimyasal bileşimi ve biyoaktif etkileri kişnişin ticari değerini etkilemektedir (Nadeem ve ark., 2013; Shams ve ark, 2016, Furan ve Geboloğlu, 2017). Kişniş meyvesi \% 0.03-2.6 arasında değişen oranlarda uçucu yağ içermektedir. Kişniş meyvelerinin uçucu yağında en fazla linalool, $\gamma$-terpinene ve $\alpha$-pinene bileşenleri bulunmaktadır. $\mathrm{Bu}$ bileşenlerden \% 50-60 arasında değişen linalool oluşturur.

Kişnişte tohum verimi, genetik yapı, iklim ve tarımsal faktörler gibi pek çok faktöre bağlı olarak değişiklik göstermektedir. Bundan dolayı yapılan çeşitli araştırmalarda tohum veriminin $50 \mathrm{~kg} \mathrm{da}^{-1}$ 'dan $300 \mathrm{~kg}$ $\mathrm{da}^{-1}$ kadar değiştiği rapor edilmiştir (Carrubba ve ark., 2006, Zheljazkov ve ark., 2008, Ghobadi ve Ghobadi,
2010, Moosavi ve ark., 2012, Nowak ve Szemplinski, 2014). $\mathrm{Bu}$ araştırma, Siirt koşullarında kişniş genotiplerinin verim ve bazı tarımsal özelliklerini belirlemek amacıyla yürütülmüsstür.

\section{MATERYAL ve YÖNTEM}

$\mathrm{Bu}$ araştırma Siirt Üniversitesi Ziraat Fakültesine ait deneme alanında 2016 yılında yürütülmüştür. İklim özellikleri bakımından nisan-temmuz dönemine ait toplam yağış miktarı $154.5 \mathrm{~mm}$, sıcaklık ortalamaları $24.8{ }^{\circ} \mathrm{C}$ ve hava nispi nem değeri $\% 34.15$ olmuştur (Anonim, 2016). Deneme alanı toprakları killi, hafif alkali karakterde, tuzsuz, kireçli, organik madde ve bitkilere yarayışlı fosfor yönünden fakir, potasyum, demir, bakır yönünden yeterli, çinko ve mangan içerikleri ise düşük seviyededir. Denemede materyal olarak; Gamze, Erbaa, Pelmus, Kudret K çeşitleri ile Irak ve Siirt populasyonları kullanılmıştır. Denemede ekim işlemi 5 Nisan 2016 tarihinde yapılmış olup meyvelerin \% 50'sinin sarımsi-kahverengi renk aldığ 1 dönemde hasat işlemine başlanmıştır. Araştırma sonunda elde edilen veriler JUMP programı kullanılarak varyans analizi yapılmış ve ortalamalar arasındaki farklılıklara Tukey çoklu karşılaştırma testi uygulanmıştır (Açıkgöz ve Açıkgöz, 2001). 


\section{BULGULAR ve TARTIŞMA \\ Fenolojik Gözlemler}

Araştırmada fenolojik gözlemlere ait değerler Çizelge 1'de verilmiştir. Fenolojik gözlemlerden elde edilen değerler ile yapılan istatistiki analiz sonucunda genotipler arasında istatistiki olarak 0.01 önemlilik düzeyinde farklılık bulunmuştur. En erken çıkış süresi Irak populasyonunda tespit edilmiş olup onu Siirt populasyonu izlemiştir. En geç çıkış ise Kudret $\mathrm{K}$ ve Pelmus çeşitlerinde belirlenmiştir. İlk çiçeklenme ve vejetasyon süresi çıkış süresi ile benzerlik göstermektedir. İlk çiçeklenme süresi Irak populasyonunda 46 gün, Pelmus populasyonunda 56 gün, vejetasyon süresi Irak populasyonunda 68 gün, Kudret K populasyonunda 93 gün olarak gerçekleşmiştir (Çizelge 1).

Çizelge 1. Kişniş genotiplerinin çıkış süresi, ilk çiçeklenme süresi ve vejetasyon süresine ait ortalama değerler

\begin{tabular}{lccc}
\hline Genotipler & Çıkış süresi (gün) & İlk çiçeklenme süresi (gün) & Vejetasyon süresi (gün) \\
\hline Kudret K & $20 \mathrm{~d}$ & $55 \mathrm{c}$ & $93 \mathrm{c}$ \\
Pelmus & $20 \mathrm{~d}$ & $56 \mathrm{c}$ & $89 \mathrm{c}$ \\
Gamze & $17 \mathrm{bc}$ & $54 \mathrm{bc}$ & $91 \mathrm{c}$ \\
Erbaa & $18 \mathrm{c}$ & $52 \mathrm{bc}$ & $90 \mathrm{c}$ \\
Irak & $15 \mathrm{a}$ & $46 \mathrm{a}$ & $68 \mathrm{a}$ \\
Siirt & $16 \mathrm{ab}$ & $49 \mathrm{ab}$ & $78 \mathrm{~b}$ \\
\hline Ortalama & 17.67 & 43.33 & 84.83 \\
\hline Önemlilik düzeyi & 0.0001 & 0.0002 & 0.0001 \\
\hline CV $(\%)$ & 4.64 & 4.20 & 3.80 \\
\hline
\end{tabular}

$\mathrm{CV}$ : Varyasyon katsayısı

\section{Bitki Boyu}

Genotipler arasında bitki boyu bakımından istatistiki olarak 0.05 önemlilik düzeyinde farklılık bulunmuştur (Çizelge 2). En yüksek bitki boyu $71.70 \mathrm{~cm}$ ile Pelmus çeşitinde, en düşük bitki boyu ise $51.22 \mathrm{~cm}$ ile Irak populasyonunda belirlenmiştir. Bitki boyu genotiplere bağlı olarak değişen bir özellik olmakla birlikte ekolojik faktörlerden ve kültürel uygulamalardan etkilenebilmektedir. Bitki boyunun çeşitlere göre değişiklik gösterdiği yapılan çalışmalarda da belirtilmiştir (Kan ve İpek, 2002; Uzun ve ark., 2010; Yurum, 2012; Gücük, 2014; Demir, 2015; Aydın, 2016; Kalkan, 2016; Yalçın, 2016).

\section{Sap Kalınlı̆̆}

Genotipler arasında sap kalınlığ 1 bakımından istatistiki olarak 0.05 önemlilik düzeyinde farklılık bulunmuştur. En yüksek sap kalınlığı Gamze (2.34 mm) çeşitinde, en düşük sap kalınlığı ise Irak $(1.98 \mathrm{~mm})$ populasyonunda saptanmıştır. Kudret K, Pelmus, Erbaa, Siirt genotipleri istatistiki olarak aynı grupta yer almıştır. Sap kalınlığının genotiplere göre değişiklik gösterdiği farklı ekolojilerde yürütülen çalışmalarda da bildirilmiştir (Karaca ve Kevseroğlu, 2001; Uzun ve ark., 2010).

Çizelge 2. Kişniş genotiplerinin bitki boyu, sap kalınlığı, bitki başına şemsiye sayısı, şemsiye başına tohum sayısı, 1000 meyve ağırlığı, biyolojik verim, tohum verimi ve hasat indeksine ait ortalama değerler

\begin{tabular}{|c|c|c|c|c|c|c|c|c|c|}
\hline Genotipler & $\begin{array}{l}\text { Bitki } \\
\text { boyu } \\
(\mathrm{cm})\end{array}$ & $\begin{array}{c}\text { Sap } \\
\text { kalınlığ } \\
1(\mathrm{~mm})\end{array}$ & $\begin{array}{c}\text { Dal } \\
\text { say1s1 } \\
\text { (adet) }\end{array}$ & $\begin{array}{c}\text { Şemsiy } \\
\text { e sayısı } \\
\text { (adet) }\end{array}$ & $\begin{array}{c}\text { Şemsiyede } \\
\text { meyve } \\
\text { say1s1 } \\
\text { (adet) }\end{array}$ & $\begin{array}{c}1000 \\
\text { meyve } \\
\text { ağırlığ }(\mathrm{g})\end{array}$ & $\begin{array}{c}\text { Biyolojik } \\
\text { verim } \\
\left(\mathrm{kg} \mathrm{da}^{-1}\right)\end{array}$ & $\begin{array}{c}\text { Meyve } \\
\text { verimi } \\
\left(\mathrm{kg} \mathrm{da}^{-1}\right)\end{array}$ & $\begin{array}{c}\text { Hasat } \\
\text { indeks } \\
\mathrm{i} \\
(\%)\end{array}$ \\
\hline Kudret K & $56.00 \mathrm{ab}$ & $2.26 \mathrm{ab}$ & $\begin{array}{l}7.14 \\
a b c\end{array}$ & $8.40 \mathrm{ab}$ & $35.80 \mathrm{ab}$ & $8.39 \mathrm{~b}$ & $599.2 \mathrm{a}$ & $109.9 \mathrm{a}$ & 18.53 \\
\hline Pelmus & $71.70 \mathrm{a}$ & $2.22 \mathrm{ab}$ & $\begin{array}{l}6.94 \\
\text { bc }\end{array}$ & $7.35 \mathrm{bc}$ & $35.80 \mathrm{ab}$ & $7.32 \mathrm{c}$ & $477.5 \mathrm{ab}$ & $110.1 \mathrm{a}$ & 23.17 \\
\hline Gamze & $55.75 \mathrm{ab}$ & $2.34 \mathrm{a}$ & $\begin{array}{l}7.49 \\
\mathrm{ab}\end{array}$ & $9.52 \mathrm{a}$ & $37.66 \mathrm{a}$ & $9.34 \mathrm{a}$ & $604.9 \mathrm{a}$ & $119.8 \mathrm{a}$ & 19.92 \\
\hline Erbaa & $67.10 \mathrm{ab}$ & $2.22 \mathrm{ab}$ & $7.76 \mathrm{a}$ & $7.96 \mathrm{~b}$ & $34.32 \mathrm{al}$ & $8.47 \mathrm{~b}$ & $614.2 \mathrm{a}$ & $112.0 \mathrm{a}$ & 18.69 \\
\hline Irak & $51.22 \mathrm{~b}$ & $1.98 \mathrm{~b}$ & $4.92 \mathrm{~d}$ & $5.60 \mathrm{c}$ & $30.21 \mathrm{~b}$ & $6.45 \mathrm{~d}$ & $338.0 \mathrm{~b}$ & $76.9 \mathrm{~b}$ & 22.70 \\
\hline Siirt & $59.79 a b$ & $2.03 \mathrm{ab}$ & $\begin{array}{l}5.93 \\
\mathrm{~cd}\end{array}$ & $6.40 \mathrm{bc}$ & $31.37 \mathrm{ab}$ & $7.81 \mathrm{c}$ & $421.6 \mathrm{ab}$ & $107.5 \mathrm{ab}$ & 23.36 \\
\hline Ortal & 60.26 & 2.18 & 6.70 & 7.54 & 34.19 & 7.96 & 509.2 & 106.0 & 21.06 \\
\hline $\begin{array}{l}\text { Önemlilik } \\
\text { düzeyi }\end{array}$ & 0.0158 & 0.0359 & 0.0001 & 0.0001 & 0.0175 & 0.0001 & 0.0005 & 0.0134 & 0.0701 \\
\hline $\mathrm{CV}(\%)$ & 12.16 & 8.17 & 4.88 & 7.52 & 7.00 & 1.71 & 13.00 & 11.02 & 13.39 \\
\hline
\end{tabular}




\section{Dal Sayts}

Araştırmada dal sayısı bakımından genotipler arasında istatistiki olarak 0.001 önemlilik düzeyinde farklılık saptanmıştır. En yüksek dal sayısı 7.76 adet ile Erbaa çeşitinde belirlenmiş olmakla birlikte Gamze çeşiti (7.49 adet) ile aralarında istatistiki olarak fark bulunmamıştır. En düşük dal sayısı 4.92 adet ile Irak populasyonunda belirlenmiştir. Farklı ekolojilerde yürütülen çalışmalarda dal sayısı bakımından genotipler arasında farklılığın belirlendiği bildirilmiştir (Demir, 2015; Kalkan, 2016; Yalçın, 2016 ).

\section{Bitki Başına Şemsiye Sayısı}

Bitki başına şemsiye sayısı üzerine genotiplerin etkisi önemli $(\mathrm{p}<0.01)$ bulunmuştur. Bitki başına şemsiye sayısı 5.60-9.52 adet arasında değişiklik göstermiştir. En fazla şemsiye sayısı Gamze çeşidinde belirlenmiştir. Ancak Kudret $\mathrm{K}$ çeşiti ile aralarında istatistiki olarak farklılık bulunmamaktadır. Farklı ekolojilerde yapılan çalışmalar bitki başına şemsiye sayısının genotipe bağlı olarak değişiklik gösterdiğini belirtmişlerdir (Uzun ve ark., 2010; Gücük, 2014; Bajad ve ark., 2017; Bajya ve ark., 2017).

\section{Şemsiye Başına Meyve Sayıs}

Şemsiye başına meyve sayısı üzerine genotiplerin etkisi $(\mathrm{P}<0.05)$ önemli bulunmuştur. Şemsiye başına meyve sayısı 30.21-37.66 adet arasında değişiklik göstermiştir. En düşük şemsiye sayısı Irak populasyonunda belirlenirken, en yüksek Gamze çeşidinde saptanmıştır. Siirt populasyonu diğer tescilli kişniş çeşitleri ile istatistiki olarak aynı grupta yer almıştır. Şemsiyede meyve sayısını farklı genotipler ile yürüttükleri çalışmalarda Tunçtürk ve Tunçtürk (2008), 12.2-38.5 adet, Aydin (2015), 13.89-33.17 adet, Arabac1 ve Bayram (2005) ise 9.4-15.5 adet olarak bildirmişlerdir.

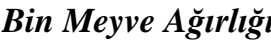

Bin meyve ağırlığ üzerine genotiplerin etkisi $(\mathrm{p}<0.01)$ önemli bulunmuştur. Kişnişte bin meyve ağırlığı en yüksek $9.34 \mathrm{~g}$ ile Gamze çeşidinde en düşük $6.45 \mathrm{~g}$ ile Irak çeşidinde belirlenmiştir. Bin meyve ağırlığını Esendal ve ark. (1995), 6.45- 6.86, Kan (2007), 9.17-11.01 g, Yurum (2012), 7.16-8.82 g, Çınarlıdere (2016), 8-16 g olarak bildirmişlerdir. Bin meyve ağırlığı yönünden kaynaklanan bu farklılığın tohumların iri ve küçük taneli olmasından, farklı iklim ve toprak koşullarından kaynaklanmış olabileceği düşünülmektedir.

\section{Biyolojik Verim}

Biyolojik verim bakımından genotipler arasında istatistiki olarak 0.001 önemlilik düzeyinde farkl1lık tespit edilmiştir. En yüksek biyolojik verim Gamze (604.9 $\mathrm{kg} \mathrm{da}^{-1}$ ) ve Erbaa (614.2 $\mathrm{kg} \mathrm{da}^{-1}$ ) genotiplerinde belirlenmiştir. Farklı genotipler ile yapılan çalışmalarda Gümüşçü ve ark. (2007), 265.2-400.7 kg da-1 Kandemir (2010), 243.19-681.95 kg da-1, Erdoğdu (2012) 365.70$527.20 \mathrm{~kg} \mathrm{da}^{-1}$, Gücük (2014) ise $690.2-860.4 \mathrm{~kg} \mathrm{da}^{-1}$ olarak bildirmişlerdir.

\section{Meyve Verimi}

Meyve verimi üzerine genotiplerin etkisi $(\mathrm{p}<0.05)$ önemli bulunmuştur. Meyve verimi kişniş genotiplerine göre 76.9-119.8 $\mathrm{kg} \mathrm{da}^{-1}$ arasında değişiklik göstermiştir. En düşük meyve verimi Irak populasyonunda belirlenmiştir. Tescilli kişniş çeşitleri arasında meyve verimi yönünden fark bulunmamaktadır. Kişnişte tohum verimi çeşitlerin genetik özellikleri, iklim ve tarımsal faktörler gibi pek çok faktöre bağlı olarak değişiklik göstermektedir. Özel ve Demirbilek (2000), kişnişte meyve verimi $79.19 \mathrm{~kg} \mathrm{da}^{-1}$, Kan ve İpek (2002) farklı genotipler ile yaptıkları çalışmada $86.6-124.3 \mathrm{~kg} \mathrm{da}^{-1}$, Şahin (2013) ise farklı ekim zamanlarında yetiştirdikleri kişnişte meyve veriminin 16.34-108.90 kg da-1 arasında değişiklik gösterdiğini bildirmişlerdir.

\section{Hasat İndeksi}

Hasat indeksi üzerine genotiplerin etkisi istatistiki olarak önemsiz bulunmuştur. Hasat indeksi \% 18.5323.36 arasında değişiklik göstermiştir. Ghobadi ve Ghobadi (2010), farklı ekim sıklıklarını araştırdıkları çalışmada, hasat indeksini \% 30.3-36.7, Gök (2011), farklı kişniş genotipleri ile yaptığ 1 çalışmada hasat indeksini \% 29-42, Meena ve ark. (2014), bitki büyüme düzenleyici ve kükürt seviyelerini araştırdıkları çalışmalarında \% 40.83-42.22 olarak bildirmişlerdir.

Araştırmada elde edilen bulgular büyük ölçüde yapılan diğer araştırma sonuçlan ile uyum göstermektedir. Bununla birlikte ortaya çıkan farklılıklar genetik yapıdan ve yetiştirildiği çevre faktörlerinin farklı olmasından kaynaklanmış olabileceği düşünülmektedir.

\section{SONUC}

Tek yıllık olarak yürütülen bu çalışmanın sonuçlarına göre Siirt koşullarında kişniş bitkisinin yazlık olarak yetiştirilebileceği belirlenmiştir. Gamze çeşidi diğer çeşitlere göre araştırmada ele alınan özellikler bakımından öne çıkmakla birlikte yeni çeşitlerin eklenerek araştırmanın birkaç yıl daha yürütülmesi daha uygun olacaktır.

\section{KAYNAKLAR}

Açıkgöz N, Açıkgöz N 2001. Tarımsal Araştırmaların İstatistiki Değerlendirilmesinde Yapılan Bazı Hatalar. 1. Tek Faktörlü Denemeler. Anadolu Dergisi, 11(1): 135-147.

Anonim 2016. Devlet Meteoroloji İşleri Genel Müdürlüğü Kayıtları.

Arabacı O, Bayram E 2005. Farklı Sira arası ve Tohumluk Miktarlarında Kişniş (Coriandrum sativum L.)'in Bazı Morfolojik ve Teknolojik Özelliklerinin Belirlenmesi. Türkiye VI. Tarla Bitkileri Kongresi, 5-9 Eylül, Antalya.

Aydın D 2015. Farklı Kişniş (Coriandrum sativum L.) Çeşitlerinde Değişik Ekim Mesafelerinin Verim ve Kalite Üzerine Etkisi. Eskişehir Osmangazi Üniversitesi, Fen Bilimleri Enstitüsü, Tarla Bitkileri ABD, Yüksek Lisans Tezi, $45 \mathrm{~s}$.

Bajad GB, Dahale, MH, Nandeshwar, VN 2017. Performance of Different Coriander Varieties for Seed Yield. J Krishi Vigyan, 5(2) :132-137.

Bajya M, Kakralya, BL, Jangid, K, Burdak, A 2017. Estimation of the Effect of Drought on Yield and Yield Contributing Traits in Coriander Genotypes 
(Coriandrum sativum L.). Int. J. Curr. Microbiol. App. Sci., 6(8): 729-736.

Carrubba A, Torre R, Saiano F, Alonzo G 2006. Effect of Sowing Time on Coriander Performance in a Semiarid Mediterranean Environment. Crop Sci., 46: 437-447.

Çınarlıdere H 2016. Farklı humik asit dozlarının yazlık ve kışlık ekilen kişniş (Coriandrum sativum L.)'in bazı tarımsal özellikleri ile uçucu yağ oranı üzerine etkileri. Bozok Üniversitesi, Fen Bilimleri Enstitüsü, Tarla Bitkileri ABD, Yüksek Lisans Tezi, 71 s.

Demir H 2015. Kahramanmaraş Koşullarında Farklı Ekim Zamanlarının Kişniş'te (Coriandrum sativum L.) Verim ve Kalite Üzerine Etkisi. Kahramanmaraş Sütçüimam Üniversitesi, Fen Bilimleri Enstitüsü, Tarla Bitkileri ABD, Yüksek Lisans Tezi, 53 s.

Erdoğdu Y 2012. Farklı Azot Dozlarının Kişniş (Coriandrum sativum L.) Bitkisinde Verim, Verim Özellikleri ve Uçucu Yağ Oranı Üzerine Etkileri. Namık Kemal Üniversitesi, Fen Bilimleri Enstitüsü, Tarla Bitkileri ABD, Yüksek Lisans Tezi, $68 \mathrm{~s}$.

Esendal E, Kevseroğlu K, Yalçıntaş G 1995. Farklı Ekim Zamanları ve Sıra Aralığının Kişniş (Coriandrum sativum L.) Bitkisinin Bazı Morfolojik Özellikleri ile Meyve Verimine Etkisi. Tıbbi ve Aromatik Bitkiler Workshop, 25-26 Mayıs, İzmir.

Furan MA, Geboloğlu MD 2017. Yetiştiriciliği Yapılan Bazı Türk Kişniş (Coriandrum sativum L.) Çeşitlerinde Genetik Çeşitliliğin ISSR ve SRAP Markörleri Yardımıyla Değerlendirilmesi. Yüzüncü Y1l Üniversitesi Tarım Bilimleri Dergisi, 27(2): 245 251.

Ghobadi ME, Ghobadi M 2010. The Effects of Sowing Dates and Densities on Yield and Yield Components of Coriander (Coriandrum sativum L.). World Academy of Science, Engineering and Technology, 4(10): 725-728.

Gök N 2011. Farklı Zamanlarda Ekilen Kişniş (Coriandrum sativum L.) Çeşitlerinin Verim ve Kalite Özelliklerinin Belirlenmesi. Yüzüncü Y1l Üniversitesi, Fen Bilimleri Enstitüsü, Tarla Bitkileri ABD, Yüksek Lisans Tezi, 57 s.

Gücük F 2014. Kazova Ekolojik Koşullarında Kışlık ve Yazlık Yetiştirilen Kişniş (Coriandrum sativum L.) Çeşit ve Hatlarının Agronomik ve Kalite Özeliklerinin Belirlenmesi. Gaziosmanpaşa Üniversitesi, Fen Bilimleri Enstitüsü, Tarla Bitkileri ABD, Yüksek Lisans Tezi, $57 \mathrm{~s}$.

Gümüşçü A, İpek A, Gümüşçü G 2007. Tescilli Kişniş (Coriandrium sativum L.) Çeşitlerinin Çumra (Konya) Koşullarında Performanslarının Belirlenmesi. Türkiye VII. Tarla Bitkileri Kongresi, 25-17 Haziran, Erzurum.

Kalkan Z 2016. Kișniş Bitkisinin (Coriandrum sativum L.) Verim, Verim Unsurları ve Bazı Kalite Özellikleri Üzerine Farklı Sıra Arası Mesafelerin Etkisi. Atatürk Üniversitesi, Fen Bilimleri Enstitüsü, Tarla Bitkileri ABD, Yüksek Lisans Tezi. 63 s.

Kan Y 2007. Konya Ekolojik Koşullarında Yetiştirilen Kişniş (Coriandrum sativum L.)'de Uygulanan
Organik ve İnorganik Gübrelerin Verim ve Uçucu Yağ Oranı Üzerine Etkileri. Selçuk Üniversitesi Ziraat Fakültesi Dergisi, 21(42): 36-42.

Kandemir K 2010. Farklı Azot Dozu ve Sıra Aralığının Kişnişin Verim ve Verim Unsurları Üzerine Etkisi. Ordu Üni., Fen Bil. Ens., Tarla Bitkileri ABD, Yüksek Lisans Tezi, $52 \mathrm{~s}$.

Meena M, Shivran AC, Deewan P, Verma R 2017. Influence of Sulphur and Zinc Fertilization on Yield Attributes, Yield and Economics of Coriander Varieties. International Journal of Current Microbiology and Applied Sciences, 6(3): 17681774.

Moosavi SG, Seghatoleslami MJ, Zareie MH 2012. The Effect of Planting Date and Plant Density on Morphological Traits and Essential Oil Yield of Coriander (Coriandrum sativum L.). Int. J. Agri. Crop Sci., 4(8): 496-501.

Nadeem M, Anjum FM, Khan, MI, Tehseen, S 2013. Nutritional and Medicinal Aspects of Coriander (Coriandrum sativum L.). British Food Journal, 115(5): 743-755.

Nowak J, Szempliěski W 2014. Influence of Sowing Date on Yield and Fruit Quality of Coriander (Coriandrum sativum L.). Acta Sci. Pol., Hortorum Cultus, 13(2): 83-96.

Özyazıcı G, Kevseroğlu K 1999. Ekim Zamanları ve Azotlu Gübre Dozlarının Kişniş Bitkisinin Verim ve Bazı Özelliklerine Etkileri. Karadeniz Bölgesi Tarım Sempozyumu Bildirileri, 4-5 Ocak, Samsun.

Kan Y, İpek A 2002. Seçilmiş Bazı Kişniş (Coriandrum sativum L.) Hatlarının Verim ve Bazı Özellikleri. 14. Bitkisel İlaç Hammaddeleri Toplantısı, ISBN 97594077-2-8, Eskişehir.

Karaca A, Kevseroğlu K 1999. Farklı Orijinli Kișniş (Coriandrum sativum L.) ve Rezene (Foeniculum vulgare Mill.) Bitkilerinin Önemli Tarımsal Özellikleri Üzerine Bir Araştırma. Ondokuz Mayıs Üniversitesi Ziraat Fakültesi Dergisi, 14(2): 65-77.

Özel A, Demirbilek T 2000. Harran Ovası Kuru Koşullarında Bazı Tek Yıllık Baharat Bitkilerinin Verim ve Bazı Agronomik Özelliklerinin Belirlenmesi, Harran Üniversitesi Ziraat Fakültesi Dergisi, 4 (3-4): 21-32.

Shams M, Ramezani M, Esfahan SZ, Esfahan, EZ, Dursun A, Y1ldirım E 2016. Effects of Climatic Factors on the Quantity of Essential Oil and Dry Matter Yield of Coriander (Coriandrum sativum L.). Indian Journal of Science and Technology, 9(6): 1-4.

Şahin B 2013. Farklı Ekim Zamanlarında Yetiştirilen Bazı Tıbbi Bitkilerin Verim ve Kalite Özelliklerinin Belirlenmesi. Selçuk Üniversitesi, Fen Bilimleri Enstitüsü, Tarla Bitkileri ABD, Yüksek Lisans Tezi, $153 \mathrm{~s}$.

Tunçtürk M, Tunçtürk R 2008. Farklı Azot Dozu Uygulamalarının Bazı Kişniş (Coriandrum sativum L.) Populasyonlarında Verim ve Verim Özelikleri Üzerine Etkisi. Y.Y.Ü. Fen Bilimleri Enstitüsü Dergisi, 13(1): 39-44. 
Uzun A, Özçelik H, Özden YŞ 2010. Orta Karadeniz Bölgesi için Geliştirilen Kişniş (Coriandrum sativum L.) Çeşitlerinin Bazı Tarımsal Özelliklerinin Belirlenmesi, Verim ve Uçucu Yağ Oranının Stabilite Analizi. GOÜ. Ziraat Fakültesi Dergisi, 27: 1-8.

Yalçın Z 2016. Bazı Kişniş Genotiplerinin (Coriandrum sativum L.) Erzurum Ekolojik Koşullarında Verim ve Başlıca Tarımsal Özellikleri. Atatürk Üniversitesi, Fen Bilimleri Enstitüsü, Tarla Bitkileri ABD, Yüksek Lisans Tezi, $50 \mathrm{~s}$.
Yurum Ç 2012. Samsun Ekolojik Koşullarında Kışlık ve Yazlık Ekim Zamanlarının Kişniş (Coriandrum sativum L.) Bitkisinin Önemli Tarımsal Özellikleri ile Kalite Kriterlerine Etkisinin Belirlenmesi. Ondokuz Mayıs Üniversitesi, Fen Bilimleri Enstitüsü, Tarla Bitkileri ABD., $99 \mathrm{~s}$.

Zheljazkov VD, Pickett KM, Caldwell CD, Pincock JA, Roberts JC, Mapplebeck L 2008. Cultivar and Sowing Date Effects on Seed Field and Oil Composition of Coriander in Atlantik Canada. Indust. Crops Prod., 28: 88-94. 